\title{
Teores de Carboidratos Não-Estruturais, Nitrogênio Total e Peso de Raízes em Coastcross-1 (Cynodon dactylon (L.) Pers) Pastejado por Ovinos
}

\author{
Ulysses Cecato ${ }^{1}$, Clovenilson Cláudio Perissato Cano ${ }^{3}$, Marcelino Bortolo 3 , Valdo Rodrigues \\ Herling ${ }^{4}$, Marcos Weber do Canto ${ }^{1}$, Christian Roberto de Carvalho Castro ${ }^{2}$
}

\begin{abstract}
RESUMO - O experimento foi realizado no período de outubro de 1997 a abril de 1998, com o objetivo de avaliar os teores de carboidratos não-estruturais (CHO), nitrogênio total (NT) e produção de raízes em pastagem de Coastcross-1 (Cynodon dactylon (L.) Pers), em quatro níveis de resíduo de matéria seca (RMS: 1978, 2130, 2545 e 3857 kg de MS/ha), sob pastejo contínuo e lotação variável. O delineamento experimental utilizado foi inteiramente casualizado, com duas repetições. As avaliações dos teores de CHO e NT foram estudadas nas raízes e base do colmo, em função dos níveis de resíduo de matéria seca (RMS) e do tempo (dias) do experimento. Os resultados observados evidenciam que os teores de CHO nas raízes e a porcentagem de NT na base de colmo não foram influenciados pelos níveis de RMS e período de coleta. Os maiores teores de CHO na base do colmo foram encontrados a partir do resíduo de $2545 \mathrm{~kg}$ de MS/ha, e no tempo houve constante adaptação às condições de pastejo. O teor de CHO foi superior na base do colmo, comparada às raízes. A porcentagem de NT nas raízes diminuiu até o nível de $2545 \mathrm{~kg}$ de MS/ha. A produção de matéria seca de raízes aumentou, à medida que aumentou os RMS, ocorrendo declínio em relação ao período de coleta.
\end{abstract}

Palavras-chave: colmo, lotação variável, reservas, resíduo de matéria seca

\section{Nonstructural Carbohydrates, Total Nitrogen and Weight of Roots in Coastcross-1 (Cynodon dactylon (L.) Pers) Grazed by Sheep}

\begin{abstract}
The experiment was conducted from October 1997 to April 1998, to evaluate the nonstructural carbohydrates (SC), total nitrogen (TN) and roots weight, of the pasture of Coastcross - 1 (Cynodon dactylon (L.) Pers), under four levels of dry matter residue (DMR: 1978, 2130, 2545 and $3857 \mathrm{~kg} \mathrm{DM} / \mathrm{ha}$ ), under continuous stocking (put and take). A completely randomized design, with two replications, was used. SC and TN contents were analysed on roots and stem base according to dry matter residue levels (DMR) and time (days) of sampling. SC in the roots and percentage of TN in the stem base were not influenced by levels of DMR and sampling period. The highest SC in the stem base was found in the residue of $2545 \mathrm{~kg} \mathrm{DM} / \mathrm{ha}$, and was observed an adaptation to the pasture condictions as time progressed. SC was higher in the stem base compared with the roots. TN percentage in the roots decreased until the leavel of $2545 \mathrm{~kg} \mathrm{DM} / \mathrm{ha}$. Dry matter production of roots increased as DMR increased, but declined as the sampling period progressed.
\end{abstract}

Key Words: dry matter residue, reserves, variable stocking, stem

\section{Introdução}

As condições físicas do solo, nutrientes, umidade, temperatura e grau de desfolha têm grande influência na produção de forrageiras e, conseqüentemente, na produção animal. Estes fatores atuam diretamente sobre o sistema radicular, que é o suporte e a base para a produção de perfilhos e folhas, e, portanto, a produção de forragem.

O sistema radicular desenvolve-se sob a influência de diversos fatores, como a forma de utilização da pastagem, presença de pragas e moléstias, competição com outras plantas, presença de microrganismos e de aspectos que irão determinar a intensidade de crescimento e o potencial de extração de nutrientes pelas raízes.

É amplamente reconhecido que a remoção da parte aérea através do corte ou pastejo de forma muito intensa e freqüente leva ao declínio da produção das plantas. Primeiro ocorre prejuízo às raízes e, posteriormente, se manifesta na parte aérea.

Quando o tecido fotossintético residual deixa a planta em equilíbrio quanto à fotossíntese e respiração, o novo crescimento é mantido com o produto proveniente da fotossíntese. Isso significa que a altura do pastejo ou do corte afetando a quantidade de

\footnotetext{
${ }^{1}$ Professores do Depto de Zootecnia da UEM, Av. Colombo, 5790, 87080-100 - Maringá - PR Pesquisador do CNPq. E.mail: ucecato@uem.br 2 Acadêmico do curso de Zootecnia e Bolsista PET da UEM.

3 Pós-graduando do Mestrado em Zootecnia da UEM.

4 Professor do Deptô de Zootecnia - USP - Pirassununga, SP
} 
tecido fotossintético remanescente determina ou não o uso de reservas orgânicas armazenadas.

Se a altura de pastejo ou do corte favorecer a manutenção de um índice de área foliar adequado, ocorrerá adequada interceptação de energia luminosa, favorecendo o crescimento inicial das plantas. Então, um bom manejo é importante para melhorar a recuperação e produção das plantas forrageiras. Para isto também devem ser considerados os carboidratos de reserva $(\mathrm{CHO})$, que são utilizados pela planta como nutrientes para a sua mantença e o desenvolvimento de futuros perfílhos e raízes (MAY, 1960).

Segundo BRISKE (1991), os CHO são usados apenas para a respiração e manutenção de raízes poucos dias após a desfolhação. Salienta, também, a importância da rápida recuperação do índice de área foliar (IAF) após corte ou desfolha, bem como sugere que outros compostos como proteínas, ácidos orgânicos e hemicelulose poderiam também contribuir com energia para a rebrota.

Quando os fatores do meio ambiente são favoráveis (luz, temperatura, umidade e fertilidade do solo, dentre outros), a velocidade da rebrota das pastagens está associada ao IAF, à concentração de carboidratos não-estruturais que a planta utiliza para a rebrota e produção de afilhos, bem como ao número de meristemas apicais que escapam à desfolha (EUCLIDES et al., 1989).

RODRIGUES (1984), ao avaliar níveis de oferta de matéria seca de capim-elefante "cv. Mott" em pastejo contínuo, obteve teores de CHO de 8,1 e 10,9\%, respectivamente, para 250 e $2500 \mathrm{~kg}$ de MS de folha residual mantidos na pastagem. Verificou também que, em pastejo rotativo, as maiores pressões de pastejo (250 e $900 \mathrm{~kg}$ de MS de folha residual) e os menores ciclos de pastejo foram responsáveis pelas menores concentrações de carboidratos não- estruturais.

Trabalhando com o capim Brachiaria (Brachiaria decumbens Stapf), submetida a 0, 1, 2 e 3 cortes a $20 \mathrm{~cm}$ de altura, 62 dias após um corte de uniformização, REIS (1981) verificou que, nas plantas não-cortadas, o teor médio de $\mathrm{CHO}$ das raízes, foi de $2,9 \%$, enquanto, naquelas cortadas apenas uma vez, de 2,6\%, ao longo de oito avaliações entre dezembro e abril. Nas raízes das plantas não-cortadas, os teores foram aumentando gradativamente a partir de dezembro (1,3\%) até março $(4,5 \%)$ e apresentaram queda em abril $(3,7 \%)$. As plantas submetidas a dois (dezembro e fevereiro) e três cortes (dezembro, fevereiro e março) apresentaram, em abril, teor de CHO nas raízes (3,6 e 3,7\% respectivamente) semelhante ao das plantas não- cortadas. Os teores de CHO na base dos colmos foram sempre superiores aos das raízes.

O nitrogênio é considerado como o principal nutriente para as plantas, sendo exigido em quantidades substanciais. Os teores de nitrogênio total tendem a ser mais elevados na parte aérea do que nas raízes. Quando ocorre deficiência de N, as formas solúveis são reduzidas nos tecidos. Prosseguindo a deficiência, ocorre a mobilização do N-protéico dos tecidos mais velhos para os mais novos. Por outro lado, quando o nível de $\mathrm{N}$ supera o necessário para o crescimento, as formas solúveis começam a acumular-se nos tecidos (MILLS e JONES, 1979).

Em trabalho de revisão, VOLENEC et al. (1996) relataram resultados para gramíneas em que o $\mathrm{N}$ armazenado contribuiu para a rebrota da parte aérea, e a desfolha causou grande variação nas relações fonte-dreno de $\mathrm{N}$, sendo que os tecidos das raízes atuam como fonte e a rebrota da parte aérea como forte dreno. Também relatam que as bases dos colmos contribuem com aproximadamente $55 \%$ e as raízes, $45 \%$ do $\mathrm{N}$ armazenado para a rebrota da parte aérea.

As raízes têm muita importância para o crescimento das plantas forrageiras, pois sustentam o desenvolvimento da parte aérea. Nesse sentido, MORAES (1991), estudando o comportamento da massa radicular do capim-pangola, verificou redução de $50 \%$ desta na condição de pressão de pastejo alta $(3,5 \% \mathrm{PV})$ em relação à baixa pressão $(10,5 \% \mathrm{PV})$. Isto explica o fato de que, dependendo do nível de desfolhação, o crescimento radicular é reduzido, cessa ou até mesmo pode ocorrer morte de raízes como consequiência da falta de energia proveniente da fotossíntese (BRISKE, 1991).

Considerando o papel fundamental desempenhado pelos carboidratos e pelo nitrogênio no metabolismo e crescimento das plantas forrageiras, objetivou-se com o presente trabalho avaliar as quantidades de carboidratos solúveis e nitrogênio total, nas raízes e na base de colmo da grama Coastcross-1, buscando subsídios para aperfeiçoar os sistemas de manejo e de utilização desta forrageira.

\section{Material e Métodos}

O experimento foi conduzido no Campus do Arenito (CAR), no município de Cidade Gaúcha, Noroeste do Paraná. Esta região situa-se a $23^{\circ} 25^{\prime}$ de latitude Sul, $51^{\circ} 55^{\prime}$ de longitude Oeste e $554,9 \mathrm{~m}$ de altitude. Oclima predominante, segundoCORRÊA(1996), 
é classificado como subtropical úmido mesotérmico com verões quentes, geadas pouco freqüentes e tendências de concentração de chuvas nos meses de verão.

O solo é classificado como Podzólico vermelhoamarelo de textura média (SECRETARIA DO ESTADO DO PARANÁ, 1985) e apresentou a seguinte composição química antes da calagem: $\mathrm{pH} \mathrm{em} \mathrm{CaCl}_{2}$ $=4,9 ; \mathrm{pH} \mathrm{em} \mathrm{H}_{2} \mathrm{O}=6,1 ; \mathrm{Al}=0,00\left(\mathrm{cmol} \mathrm{c} / \mathrm{dm}^{3}\right)$; $\mathrm{H}^{+} \mathrm{Al}^{+3}=2,45 ; \mathrm{Ca}+\mathrm{Mg}^{+2}=1,34 ; \mathrm{Ca}^{+2}=0,89$; $\mathrm{K}^{+2}=0,17$ (valores em meq/100 cm3 de solo); $\mathrm{P}=1,0 \mathrm{mg} / \mathrm{dm}^{3} ; \mathrm{C}=6,00 \mathrm{~g} / \mathrm{dm}^{3}$. Com base nos dados da análise do solo, foi feita correção deste solo com calcário calcítico, em agosto de 1997, para a elevação da saturação de bases em $65 \%$.

A área do experimento possuía 2,3 hectares onde foi estabelecida a pastagem de grama Coastcross-1 (Cynodon dactylon (L.) Pers), dividida em oito piquetes (unidade experimental), com aproximadamente $2900 \mathrm{~m}^{2}$ cada, com o uso de cerca elétrica. A disponibilização de água e sal mineral foi feita por bebedouros e cochos distribuídos em cada piquete.

A área foi adubada em função da análise do solo. A adubação com fósforo e potássio foi realizada à lanço, e em cobertura, na forma de superfosfato simples e cloreto de potássio, respectivamente, em 15/10/97 em uma aplicação, na dosagem de $120 \mathrm{~kg} /$ ha de $\mathrm{P}_{2} \mathrm{O}_{5}$ e $100 \mathrm{~kg} / \mathrm{ha}$ de $\mathrm{K}_{2} \mathrm{O}$. A adubação nitrogenada (200 $\mathrm{kg}$ de $\mathrm{N} / \mathrm{ha}$ ) foi fracionada em quatro aplicações, na forma de uréia.

Em 12/12/97, foram colocadas, na área, as ovelhas para adaptação ao manejo com cerca elétrica e rebaixamento da pastagem. Em 06/01/98, teve início período o experimental, que durou 84 dias.

Os tratamentos inicialmente estabelecidos para as avaliações foram: T1: 800; T2: 1500; T3: $2200 \mathrm{e}$ T4: $2900 \mathrm{~kg}$ de resíduo de matéria seca (RMS) por hectare, distribuídos inteiramente ao acaso nos piquetes, em duas repetições. No entanto, como tratamentos, utilizaram-se os resíduos reais estimados obtidos em cada piquete, sendo: T1: 1978; T2: 2130; T3: 2545 e T4: $3857 \mathrm{~kg}$ de MS/ha.

Para a avaliação foram utilizadas ovelhas da raça Corriedade e mestiças Bergamacia x Corriedade com idade média de 2,5 anos e o método de condução de pastejo utilizado foi contínuo com lotação variável, com ajustes de carga animal para manter os resíduos nos níveis desejados, conforme MOTT e LUCAS (1952).

As estimativas do RMS na pastagem foram feitas a intervalos de 21 dias, pelo método da dupla amostragem (WILM et al., 1944). Para isso foram coletadas cinco amostras em cada piquete, estimadas visualmente, cortadas ao nível do solo, pesadas e secas em estufas com ar forçado a $65^{\circ} \mathrm{C}$. Utilizando-se os valores das amostras cortadas e estimadas visualmente, foi feito o cálculo do nível de matéria seca em kg/ha, utilizando-se a equação de GARDNER (1986). A produção de matéria seca (PMS) encontrada nos resíduos foi de T1: 4488; T2: 6471; T3: 7379 e T4: $6629 \mathrm{~kg}$ de MS/ha.

As amostragens das raízes e base de colmo foram feitas a cada 21 dias, coletando-se uma área de $0,022 \mathrm{~m}^{2}$, em três áreas escolhidas ao acasos em cada piquete, nos respectivos tratamentos. Imediatamente após a coleta, as raízes foram lavadas em água corrente, em peneira de malha de $2 \mathrm{~mm}$, e as frações separadas em raízes e base de colmos ( a $5 \mathrm{~cm}$ do nível do solo). Imediatamente após a lavagem, estas foram congeladas em freezer para posterior secagem, a $65^{\circ} \mathrm{C}$, por 72 horas, em estufa de circulação de ar forçada. As amostras foram moídas para determinação dos teores de carboidratos não-estruturais, segundo a técnica desenvolvida por SMITH (1973). Os teores de nitrogênio total foram determinados, de acordo com a metodologia descrita por SILVA (1990).

Para a análise estatística utilizou-se o delineamento inteiramente casualizado, com quatro tratamentos (T1: 1978; T2: 2130; T3: 2545 e T4: 3857 kg de MS/ha) com duas repetições e amostra composta.

$\mathrm{O}$ estudo do efeito dos tratamentos foi feito por meio de análise de regressão, adotando-se a metodologia de superfície de resposta, a partir do modelo polinomial quadrático a duas variáveis independentes, dado por:

$$
\begin{gathered}
Y_{i j k}=b_{0}+b_{1} R_{i}+b_{2} T_{j}+b_{3} R_{i}^{2}+b_{4} T_{j}^{2}+ \\
b_{5} R_{i} T_{j}+e_{i j k}
\end{gathered}
$$

em que $Y_{\mathrm{ijk}}=$ variáveis dependentes; $b_{0}=$ constante geral; $b_{1} ; b_{2} ; b_{3} ; b_{4} ; b_{5}=$ coeficientes de regressão; $\mathrm{R}_{\mathrm{i}}=$ efeito do nível de resíduo de MS/ha i, (i=1, 2, 3 e 4); $T_{j}=$ efeito das datas de coletas (amostragens) $\mathrm{j},\left(\mathrm{j}=1,2,3,4\right.$ e 5); $\mathrm{e}_{\mathrm{ijk}}=$ erro aleatório de cada observação $Y_{i j k}$.

A partir do modelo completo acima apresentado, a escolha da equação que melhor se ajustou aos dados baseou-se no coeficiente de determinação $\mathrm{R}^{2}$, na significância da regressão e nos desvios da regressão testados pelo teste $\mathrm{F}$ (até 5\% de probabilidade) e na significância dos coeficientes de regressão testados pelo teste $\mathrm{t}$ de Student (até $10 \%$ de probabilidade). Algumas variáveis que não se ajustaram às equações pela análise de superfície de resposta e outras foram apresentados por meio dos valores médios daqueles parâmetros. 


\section{Resultados e Discussão}

Os teores de carboidratos solúveis na base de colmo (CC), em função dos níveis de RMS e do período de amostragem, estão demonstrados na Figura 1, ocorrendo relação positiva entre eles $(\mathrm{P}<0,05)$. À medida que ocorreu incremento no RMS, os teores de carboidratos reduziram-se até, aproximadamente, o nível de $2545 \mathrm{~kg}$ de MS/ha, e, a partir deste, houve incremento mais acentuado, sendo o maior teor $(3,86 \%)$ encontrado no resíduo de $3857 \mathrm{~kg}$ de $\mathrm{MS} / \mathrm{ha}$ respectivamente.

Estes resultados obtidos estão de acordo com observações encontradas na literatura, pois, segundo SPITARELI et al. (1994), nos maiores níveis de RMS, por estarem com maior quantidade de folhas verdes e, conseqüentemente, maior quantidade de tecido fotossintetizante, verifica-se maior teor de carboidratos não-estruturais, uma vez que, segundo esses autores, o manejo na pastagem que permite severa desfolhação normalmente está associado a baixo teor de carboidratos não-estruturais nas raízes e na base do colmo.

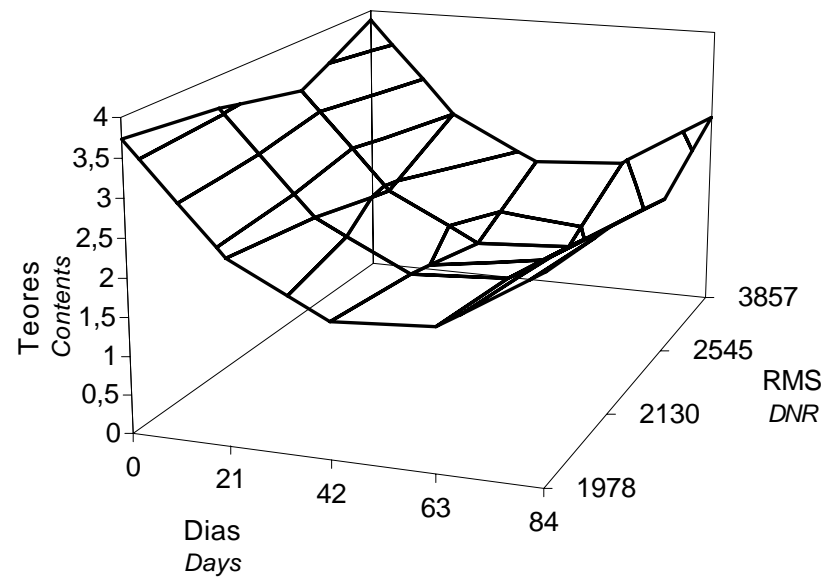

Figura 1 - Teores de carboidratos não-estruturais na base de colmo (CC) em relação aos níveis de RMS e às datas de coletas em pastagem de Coastcross-1 (Cynodon dactylon (L.) Pers). $\mathrm{P}<0,05 \quad \mathrm{Y}=8,5968$ $-0,003754(\mathrm{R})-0,08174(\mathrm{~T})+0,0000006548\left(\mathrm{R}^{2}\right)$ $+0,0008159\left(T^{2}\right) \quad R^{2}=0,68$.

Figure 1 - Non structural carbohydrates in stem base (CS) according to DMR levels and sampling dates in Coastcross-1 pasture (Cynodon dactylon (L.) Pers). P<.05; $Y=8.5968-0.003754(R)-0.08174(T)+$ $0.0000006548\left(R^{2}\right)+0.0008159\left(T^{2}\right) ; R^{2}=.68$.

Quanto ao período de coleta (dias), ocorreu efeito quadrático $(\mathrm{P}<0,05)$, sendo que os teores de carboidratos não-estruturais, inicialmente, apresentaram acréscimo, no período intermediário, redução e no final, novo acréscimo. Os maiores valores iniciais encontrados nas plantas deveram-se ao fato destas estarem com suas reservas praticamente intactas, com o passar do tempo e desfolha da pastagem pelos animais houve redução dos mesmos. O acúmulo no período final, nos níveis maiores de RMS, já foi evidenciado na literatura (RODRIGUES, 1984; CECATO, 1985; SPITARELI et al., 1994), na qual se constata a presença de maior resíduo de folhas, conseqüentemente, haverá maior acúmulo de carboidratos de reserva na base de colmo das plantas. Isto é muito importante para as plantas numa fase crítica que necessitarão de reservas para manter-se respirando e favorecendo a rebrota (MAY, 1960; NELSON e SMITH, 1968; SMITH, 1981; BRISKE, 1991).

Os teores de carboidratos não-estruturais nas raízes $(\mathrm{CHOR})$ não apresentaram diferenças $(\mathrm{P}>0,05)$ em relação aos níveis de RMS, como também em relação às datas de amostragem (Tabela 1). Os valores médios oscilaram entre 1,99 e $2,38 \%(\mathrm{P}>0,05)$, em relação aos níveis 1978 a 3875 de RMS, e entre $1,60$ e $2,72 \%$ ( $P>0,05)$, no período do experimento. Estes resultados ocorreram devido ao uso do pastejo com lotação contínua, fazendo com que as plantas tivessem constante taxa de utilização de carboidratos não-estruturais para a respiração e manutenção das raízes (BRISKE, 1991). Isto pode indicar constante adaptação da planta às condições em que estava sendo pastejada, em relação a sua área foliar nos diferentes níveis de RMS e ao longo do tempo do experimento.

A concentração de carboidratos não-estruturais na base de colmo encontrada no presente experimento foi superior ao das raízes, concordando com os resultados verificados por outros autores REIS (1981) e CECATO (1985).

A porcentagem de nitrogênio total na base de colmo (NC) não apresentou diferenças significativas $(\mathrm{P}>0,05)$ em relação aos níveis de resíduo, como também ao longo do período de coleta (Tabela 2). Os valores médios de $\mathrm{N}$ encontrados oscilaram entre 0,67 e $0,74 \%$ da MS em relação aos níveis de RMS e no tempo (dias) da amostragem, 0,66 e $0,75 \%$. Os resultados encontrados no presente experimento estão de acordo com os relatos feitos por VOLENEC et al. (1996), os quais verificaram que a porcentagem de nitrogênio na base dos colmos é superior à das raízes para gramíneas. 
648 Rev. bras. zootec.

Tabela 1 - Teores de carboidratos não-estruturais nas raízes (CR) em relação aos níveis de RMS e às datas de coletas, em pastagem de Coastcross-1 (Cynodon dactylon (L.) Pers)

Table 1 - Nonstructural carbohydrates in the roots (CR), according to DMR levels and sampling dates in Coastcross-1 pasture (Cynodon dactylon (L.) Pers)

\begin{tabular}{lcccccc}
\hline & \multicolumn{5}{c}{$\begin{array}{c}\text { Datas de coleta } \\
\text { Sampling dates }\end{array}$} & Média \\
RMS MS/ha & $16 / 01 / 98$ & $06 / 02 / 98$ & $27 / 02 / 98$ & $20 / 03 / 98$ & $10 / 04 / 98$ & Mean \\
\cline { 2 - 5 }$R M S D M / h a$ & 1,48 & 2,88 & 2,23 & 1,43 & 2,08 & 2,02 \\
1978 & 1,77 & 2,01 & 1,90 & 2,27 & 2,02 & 1,99 \\
2130 & 1,75 & 3,07 & 1,92 & 1,76 & 2,36 & 2,17 \\
2545 & 1,41 & 2,91 & 2,71 & 2,17 & 2,71 & 2,38 \\
3857 & 1,60 & 2,72 & 2,19 & 1,91 & 2,29 & \\
\hline Média & & & & & & \\
Mean & & & &
\end{tabular}

Tabela 2 - Porcentagem de nitrogênio total na base de colmo (NC) em relação aos níveis de RMS e às datas de coletas, em pastagem de Coastcross-1 (Cynodon dactylon (L.) Pers)

Table 2 - Percentage of total nitrogen on stem base (NS), according to DMR levels and sampling dates in Coastcross-1 pasture (Cynodon dactylon (L.) Pers)

\begin{tabular}{lcccccc}
\hline & \multicolumn{5}{c}{$\begin{array}{c}\text { Datas de coleta } \\
\text { Sampling dates }\end{array}$} & Média \\
RMS MS/ha & $16 / 01 / 98$ & $06 / 02 / 98$ & $27 / 02 / 98$ & $20 / 03 / 98$ & $10 / 04 / 98$ & Mean \\
\cline { 2 - 5 }$R M S$ DM/ha & 0,70 & 0,80 & 0,66 & 0,66 & 0,68 & 0,70 \\
1978 & 0,64 & 0,74 & 0,66 & 0,66 & 0,68 & 0,68 \\
2130 & 0,60 & 0,69 & 0,70 & 0,69 & 0,69 & 0,67 \\
2545 & 0,69 & 0,77 & 0,71 & 0,71 & 0,80 & 0,74 \\
3857 & 0,66 & 0,75 & 0,68 & 0,68 & 0,71 & \\
\hline Média & & & & & & \\
Mean & & & & &
\end{tabular}

As porcentagens de nitrogênio total nas raízes $(\mathrm{NR})$ apresentaram diferenças significativas $(\mathrm{P}<0,05)$ em relação aos níveis de resíduo RMS, como também ao longo do experimento (Figura 2). As porcentagens de nitrogênio total diminuíram em todos os tratamentos, com o aumento dos dias de pastejo, enquanto o aumento do RMS $(\mathrm{P}<0,05)$ promoveu diminuição da porcentagem de nitrogênio total até o nível $2545 \mathrm{~kg}$ de MS/ha, sendo que a partir deste nível ocorreu elevação. O maior acúmulo de $\mathrm{N}$ nas raízes, com o incremento do RMS, parece ser um fato importante às plantas, pois, segundo MILLS e JONES (1979), também pode atuar como fonte de reserva para a recuperação das mesmas durante pastejo ou corte.

A queda na porcentagem de nitrogênio total nas raízes com o aumento do período de pastejo pode ser atribuída à idade da planta, porque, quando os nutrientes são suficientes para suprir o sistema radicular, as plantas normalmente não acumulam nutrientes em concentração adequada. Esta concentração varia com o estágio de crescimento e, normalmente, é maior nas plantas jovens do que nas plantas adultas. JONES (1985) verificou redução na porcentagem de nitrogênio nas raízes de milho, à medida que as plantas envelheciam.

A produção de matéria seca de raízes (MSR) nos níveis de RMS e no tempo do experimento está apresentada na Figura 3. Os resultados mostram que o aumento do RMS promoveu incremento $(\mathrm{P}<0,05)$ na produção de MSR, com queda da mesma, à medida que aumentou o período de amostragem. Os resultados obtidos estão de acordo com JONES (1985) e MORAES (1991), quando citam que a desfolhação severa causa maior redução no crescimento radicular que desfolhação moderada. Estes resultados podem ser explicados pelo fato de que, dependendo do nível de desfolhação, o crescimento radicular é reduzido, cessa ou até mesmo pode ocorrer morte de raízes como conseqüência da falta de energia proveniente da fotossíntese (BRISKE, 1991). 
CECATO et al.

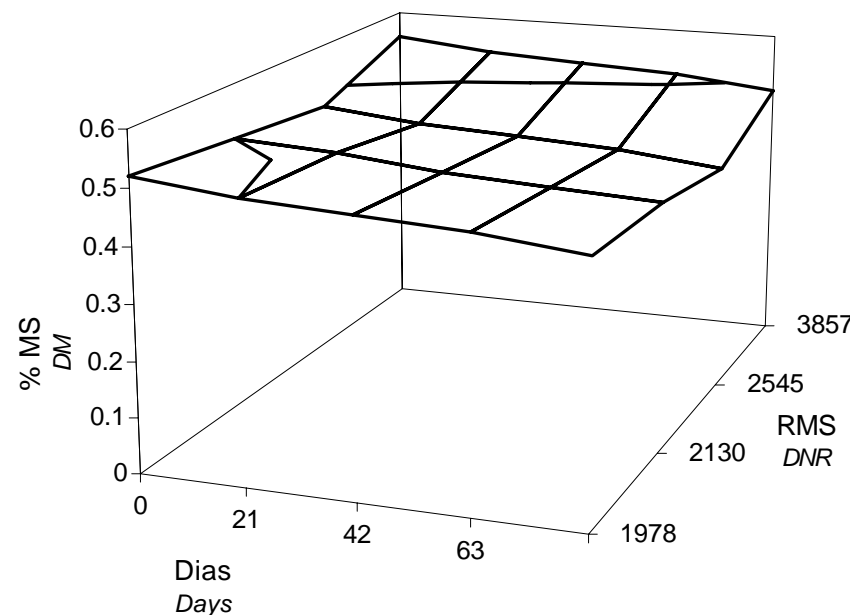

Figura 2 - Porcentagem de nitrogênio total nas raízes (NR) em relação aos níveis de RMS e às datas de coletas em pastagem de Coastcross-1 (Cynodon dactylon (L.) Pers). $\mathrm{P}<0,05$; $\mathrm{Y}=0,9833-0,0003652(\mathrm{R})-0,0006488(\mathrm{~T})+$ $0,00000006538\left(R^{2}\right) \quad R^{2}=0,64$.

Figure 2 - Percentage of total nitrogen in the roots (NR) according to DMR levels and sampling dates in Coastcross-1 pasture (Cynodon dactylon (L.) Pers). $P<.05 ; Y=0,9833$ $0.0003652(R)-0.0006488(T)+0.00000006538\left(R^{2}\right)$; $R^{2}=.64$.

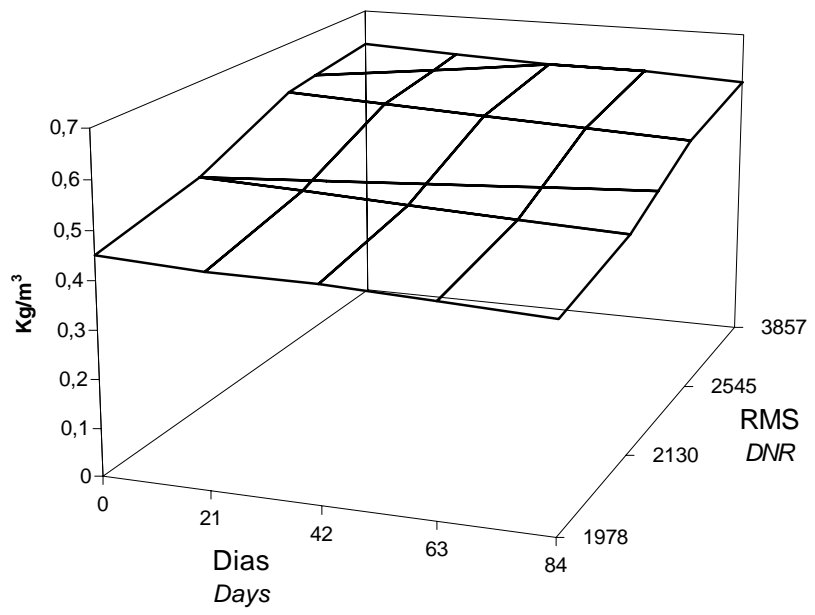

Figura 3 - Produção de matéria seca de raízes(MSR) em relação aos níveis de RMS e às datas de coletas em pastagem de Coastcross-1 Cynodon dactylon (L.) Pers). $\mathrm{P}<0,05 \quad \mathrm{Y}=-0,58339+0,0007468(\mathrm{R})$ $0,00040774(T)-0,0000001126\left(R^{2}\right) R^{2}=0,43$

Figure 3 - Production of roots dry matter (RDM) according to DMR levels and sampling dates in Coastcross-1 pasture (Cynodon dactylon (L.) Pers). $P<.05 ; Y=-0.58339$ $+0.0007468(R)-0.00040774(T)-0.0000001126\left(R^{2}\right)$; $R^{2}=.43$

\section{Conclusões}

Os resultados evidenciaram que os teores de carboidratos não-estruturais nas raízes e de nitrogênio total na base de colmo não foram influenciados pelos níveis de RMS e pelo tempo do experimento, sendo que a porcentagem de nitrogênio total nas raízes diminuiu até o nível de $2545 \mathrm{~kg}$ de $\mathrm{MS} / \mathrm{ha}$. A produção de matéria seca de raízes aumentou, à medida que se elevaram os RMS, ocorrendo declínio com o passar do período experimental.

Os teores de carboídratos de base dos colmos foram maiores que as raízes, porém, nas raízes, não foram influenciados pelos níveis de resíduo de matéria seca, no período do experimento.

O nível de resíduo de matéria seca superior a $2545 \mathrm{~kg} / \mathrm{MS} / \mathrm{ha}$ é o mais recomendado para manter adequado o nível desses elementos responsáveis pela manutenção do crescimento, pela rebrota efetiva e elevada produção da pastagem.

\section{Referências Bibliográficas}

BRISKE, D.D. 1991. Developmental morphology and physiology of grasses. In: HEITSCHMIDT, R.K., STUTH, J.W. (Eds.) Grazing management: an ecological perspective. Portland: Timber Press. p.85-108.

CECATO, U., SANTOS, G.L., BARRETO, I.L. 1985. Efeito de doses de nitrogênio e altura de corte sobre a produção, qualidade e reservas de glícidios da Setaria anceps Stapf cv. Kazangula. Rev. Centro Ciências Rurais, 15(4):367-378.

CORRÊA, A.R. 1996. Forrageiras: aptidão climática do Estado do Paraná. In: MONTEIRO, A.L.G., MORAES, A., CORRÊA, E.A.S. et al. Forragicultura no Paraná. Londrina: CPAF. p.75-92.

EUCLIDES, V.P.B., ZIMMER, A.H., VIEIRA, J.M. Equilíbrio na utilização da forragem sob pastejo. In: SIMPÓSIO SOBRE ECOSSISTEMA DE PASTAGENS, 1989, Jaboticabal. Anais... Jaboticabal: FUNEP, 1989. p.271-313.

GARDNER, A.L. 1986. Técnicas de pesquisa em pastagens e aplicabilidade de resultados em sistemas de produção. In: Medição dos atributos das pastagens em experimentos de pastejo. Brasília: EMBRAPA. p.113-140.

JONES, C.A. 1985. Defoliation. In: JONES, C.A. (Ed.) $C_{4}$ grasses and cereals: growth, development, and stress response. New York: John Wiley. p.179-189.

MAY, L.H. 1960. The utilization of carboydrate reserves in pasture plants after defoliation. Herb. Abst., 30(4):239-245.

MILLS, H.A., JONES JR., J.B. 1979. Nutrient deficiencies and toxities in plants: nitrogen. $J . P l . N u t ., 1(2): 101-122$.

MORAES, A. Produtividade animal e dinâmica de uma pastagem de pangola (Digitaria decumbens Stent), azevém (Lolium multiflorum Lam.) e trevo branco (Trifolium repens L.) submetida a diferentes pressões de pastejo. Porto Alegre, 1991. 200p. Tese (Doutorado em Zootecnia) - Universidade Federal do Rio Grande do Sul, 1991.

MOTT, G.O., LUCAS, H.L. The design, conduct and interpretation of grazing trials on cultivated and improved 
650 Rev. bras. zootec.

pastures. In: INTERNATIONAL GRASSLAND CONGRESS, 1952. Pensylvania. Proceedings... Penslyvania: State College Press, 1952. p.1380-1385.

NELSON, C.J., SMITH, D. 1968. Growth of birdsfoot trefoil and alfafa. III Changes in carbohydrate reserves and growth analysis under field condutions. Crop. Sci., 8(1):25-28.

REIS, R.A. Efeitos dos regimes de cortes nos níveis de carboidratos totais não estruturais e na produção de sementes do Capim Braquiária (Brachiaria decumbens, Stapf). Viçosa: UFV, 1981. 62p. Dissertação (Mestrado em Zootecnia) - Universidade Federal de Viçosa, 1981.

RODRIGUES, L.R.A. Morphological and physiological responses ofdwarf elephantgrass (Pennisetum purpureum (L.) Schum.) to grazing management. Florida, 1984. 192p. Thesis (Doctor of Philosophy) - University of Florida, 1984.

SECRETARIA DO ESTADO DO PARANÁ. 1985. Mapeamento dos Municípios do Estado do Paraná. Curitiba - PR. 314p.

SILVA, D.J. Análise de alimento (Métodos químicos e biológicos). Viçosa, MG: UFV, 1990. 165p.

SMITH, D. 1973. The nonstructural carboydrates. In: BUTLER, G.W., BAILEY, R.W. (Eds.) Chemistry and biochemistry of herbage. London: Academic Press. p.105-155.
SMITH, D. 1981. Removing and analysing total nonstructural carbohydrates from plant tissue. Agric. Exp. Stn. Res., p.12. SPITARELI, R.F., SOLLENBERGER, L.E., SCHANK, S.C. 1994. et al. Defoliation effects on agronomic performance of seeded Pennisetum hexaploid hybrids. Agr. J., 86:695-698.

VOLENEC, J.J., OURRY, A., JOERN, B.C. 1996. A role to nitrogen reserves in the resprout of forages and tolerance for stress. Physiologia Plantarum, 97:185-193.

WILM, H.G., COSTELlO, O.F., KLIPPLE, G.E. 1944. Estimating forage yield by the double sampling method. J. Am. Soc. Agr., 36(1):194-203.

Recebido em: 30/12/99

Aceito em: 20/01/01 